Article

\title{
Hydration Kinetics of Composite Cementitious Materials Containing Copper Tailing Powder and Graphene Oxide
}

\author{
Shuhua Liu*(1), Qiaoling Li and Xinyi Zhao \\ State Key Laboratory of Water Resources and Hydropower Engineering Science, Wuhan University, \\ Wuhan 430072, China; qllee@whu.edu.cn (Q.L.); xinyizhao@whu.edu.cn (X.Z.) \\ * Correspondence: shliu@whu.edu.cn; Tel.: +86-27-6877-2233
}

Received: 19 October 2018; Accepted: 6 December 2018; Published: 8 December 2018

check for updates

\begin{abstract}
The hydration heat evolution curves of composite cementitious materials containing copper tailing powder (CT) and graphene oxide (GO) with different contents are measured and analyzed in this paper. The hydration rate and total hydration heat of the composite cementitious materials decrease with the increase of $\mathrm{CT}$ dosage, but improve with the increase of CT fineness and GO dosage. The hydration process of the cementitious systems undergoes three periods, namely nucleation and crystal growth (NG), phase boundary reaction (I), and diffusion (D), which can be simulated well using the Krstulovic-Dabic model. The hydration rates of the three controlling processes of the composite cementitious system decrease with the increase of CT content, but improve slightly with the increase of CT fineness. GO enhances the controlling effect of the NG process of the cementitious systems with or without $\mathrm{CT}$, thus promotes the early hydration as a whole.
\end{abstract}

Keywords: composite cementitious materials; copper tailing powder; graphene oxide; hydration kinetics

\section{Introduction}

Copper tailings are waste materials generated during the purification of precious copper from the copper ores, and $128 \mathrm{t}$ copper tailings will be left over per $1 \mathrm{t}$ refined copper [1,2]. According to the United States Geological Survey Bureau, two trillion tons of copper tailings were produced worldwide in 2011 [3]. The cumulative copper tailings in China exceeded 3 trillion tons by 2014; however, only about $8.2 \%$ are recycled [3-5]. The rest are mainly disposed of in the tailing pond, which results in a lot of adverse effects. For example, the heavy metal elements in copper tailings poison the surrounding soil and water. Furthermore, as copper tailings are definitely solid gravel, the tailing pond is prone to destabilize and collapse in the case of earthquakes and flooding [6]. In addition, the construction cost and operation expense of a tailings depot are very high. As a result, the utilization of copper tailings in concrete as either fine aggregate or supplementary cementitious material is not only conducive to the resources recovery and utilization but also greatly reduces the environmental pollution, geological disasters, and other problems caused by copper tailings.

Some studies regarding the use of copper tailings as cement substitution have been conducted, and the results show that the pozzolanic activity of copper tailing powder is fairly low and its optimal replacement ratio is $5 \%$ without strength and durability reduction; however, the replacement ratio can reach up to $30-50 \%$ in mass concrete with consideration of the temperature control $[2,7,8]$. Moreover, it has been reported that graphene oxide $(\mathrm{GO})$ has reinforcing and toughening effects on the cement paste [9-13]. The improvement of the mechanism of GO can be concluded using the following reasons. The first is called the template effect, in which GO can regulate the morphology of the hydration products of cement to form flower-shaped microcrystals with uniform shape and uniform 
distribution [9-11]. The second is the nucleation effect that GO lamellae can provide nucleation sites for nucleation and crystallization of calcium silicate hydrates (C-S-H), which promotes the crystallization, nucleation, and growth of C-S-H, thereby accelerating the early hydration [12]. In addition, the interface enhancement effect between GO and C-S-H is proven to be fairly high, which may also contribute to the strength and toughness of the paste [13].

As a result, copper tailing powder (CT) shows some adverse effects on early hydration and strength of the cement-based materials, but GO can improve their microstructure and properties. What will happen when the positive and the negative elements interact? How does GO promote the hydration mechanism of a cement-CT composite system? We suppose that GO also has reinforcing and toughening effects on the composite cementitious materials containing CT. In order to investigate the effect of CT on the early hydration mechanism of cement, as well as the enhancing effect of GO on the hydration of cement and cement-CT binder, the hydration heat evolution rate and cumulative hydration heat of composite cementitious materials containing $\mathrm{CT}$ and $\mathrm{GO}$ at different contents are measured at $25{ }^{\circ} \mathrm{C}$ by an isothermal calorimeter. Based on the thermodynamic data, the hydration kinetics of the composite cementitious materials containing CT and GO are investigated in detail using the Krstulovic-Dabic model to reveal the effects of CT and GO on the early hydration.

\section{Materials and Methods}

\subsection{Raw Materials}

Ordinary Portland cement (P.O 42.5) and CT supplied by China Construction Mining Corporation are used in the experiment. Their chemical compositions, determined by the $\mathrm{X}$-ray fluorescence (XRF Axios FAST, Malvern Panalytical Ltd., Royston, UK), are listed in Table 1. CT contains a great deal of $\mathrm{CaO}, \mathrm{SiO}_{2}$, and $\mathrm{Al}_{2} \mathrm{O}_{3}$. While the total content of $\mathrm{SiO}_{2}, \mathrm{Al}_{2} \mathrm{O}_{3}$, and $\mathrm{Fe}_{2} \mathrm{O}_{3}$ is $53.03 \%$, which is less than 70\% of that put forward by ASTM C618-15 Standard Specification for Coal Fly Ash and Raw or Calcined Pozzolan for use in concrete [14]. Its XRD pattern is displayed in Figure 1; the XRD patters shows that $\mathrm{SiO}_{2}$ exists mainly in the form of andradite instead of active $\mathrm{SiO}_{2}$. In general, the $\mathrm{CT}$ used in this study has a low pozzolanic activity. GO dispersion is produced by Shanxi Institute of Coal Chemistry, Chinese Academy of Sciences, Taiyuan, China. It has a GO content of $4 \mathrm{mg} / \mathrm{mL}$ and its morphology, size (about $1 \mu \mathrm{m}$ ) and thickness (about $1 \mathrm{~nm}$ ) are characterized by the Atomic Force Microscope (AFM Tosca ${ }^{\mathrm{TM}}$ 400, Anton Paar Shanghai Trading Co. Ltd., Shanghai, China) as shown in Figure 2.

Table 1. The main chemical compositions of cement and copper tailing powder (CT)/Mass, \%.

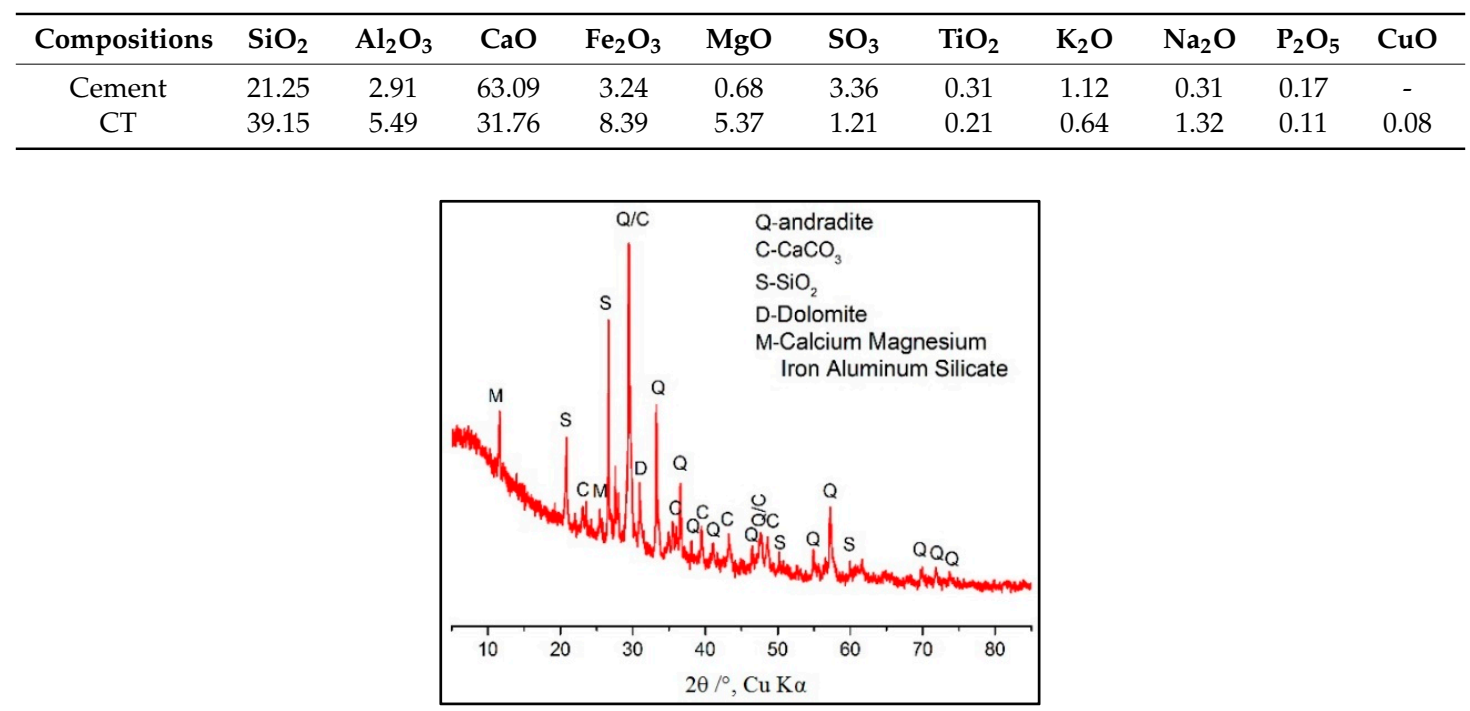

Figure 1. XRD pattern of CT. 


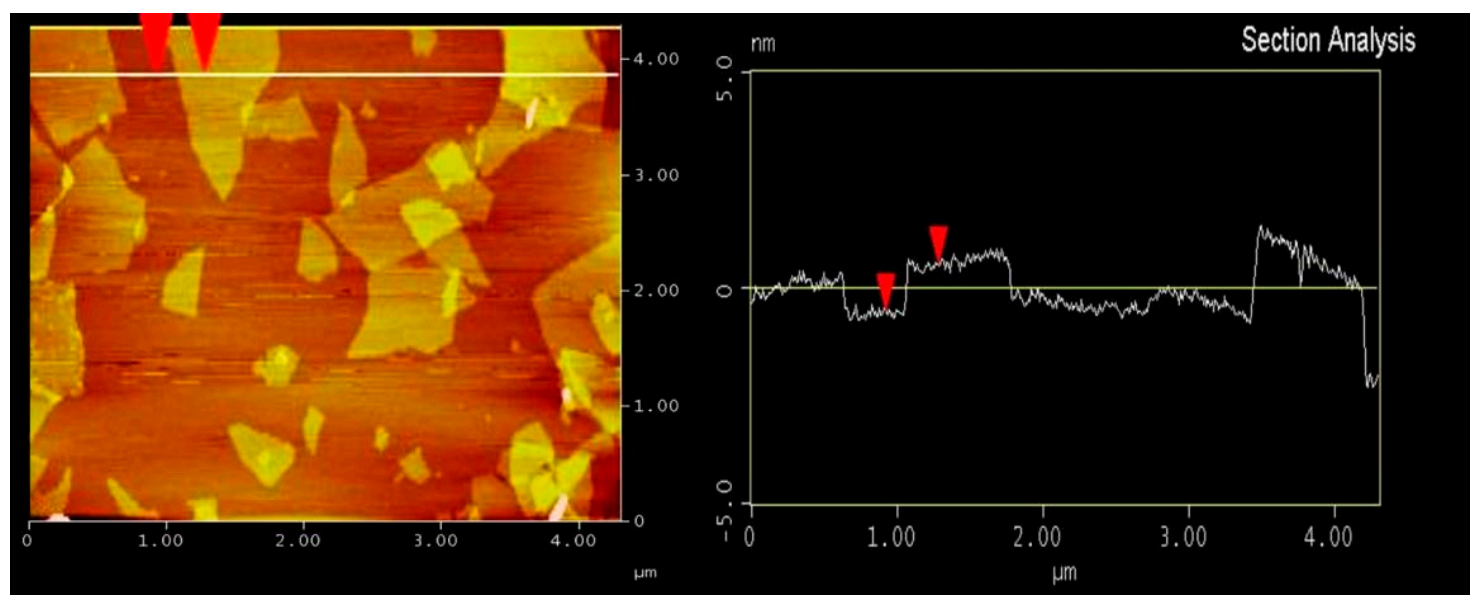

Figure 2. AFM image of graphene oxide (GO).

\subsection{Testing Methods}

The copper tailings were dried, first, at $60^{\circ} \mathrm{C}$ and filtered through a $1 \mathrm{~mm}$-square-hole sieve in order. Then, they were ground for $30 \mathrm{~min}$ and $60 \mathrm{~min}$, respectively, in a small insulative ball mill (SM 500, Daoxu Machinery Factory, Shangyu, China). The ball mill has a speed of $48 \mathrm{r} / \mathrm{min}$, with a loading capacity of $5 \mathrm{~kg}$ of sample. The powder morphology was investigated using scanning electron microscopy (JSM-5610LV, JSM Ltd., Tokyo, Japan). As shown in Figure 3, CT particles ground for $30 \mathrm{~min}$ and $60 \mathrm{~min}$ show irregular blocky, granular, and clastic shape. The particle size distribution of cement and CT, as shown in Figure 4, was measured by a laser particle size analyzer (Master size 2000, Malvern Instruments Ltd., Worcestershire, UK), ranging from 0.1 to $1000 \mu \mathrm{m}$. The specific surface area was calculated by software included in the laser particle size analyzer. The specific surface area of CT ground for $30 \mathrm{~min}$ and $60 \mathrm{~min}$ is $380 \mathrm{~m}^{2} / \mathrm{kg}$ and $690 \mathrm{~m}^{2} / \mathrm{kg}$, respectively. The specific surface area of cement is $440 \mathrm{~m}^{2} / \mathrm{kg}$. The average size of CT ground for $30 \mathrm{~min}$ and $60 \mathrm{~min}$ is $6.79 \mu \mathrm{m}$ and $3.47 \mu \mathrm{m}$, respectively, and the average size of cement is $5.67 \mu \mathrm{m}$, which is similar to their specific surface area.

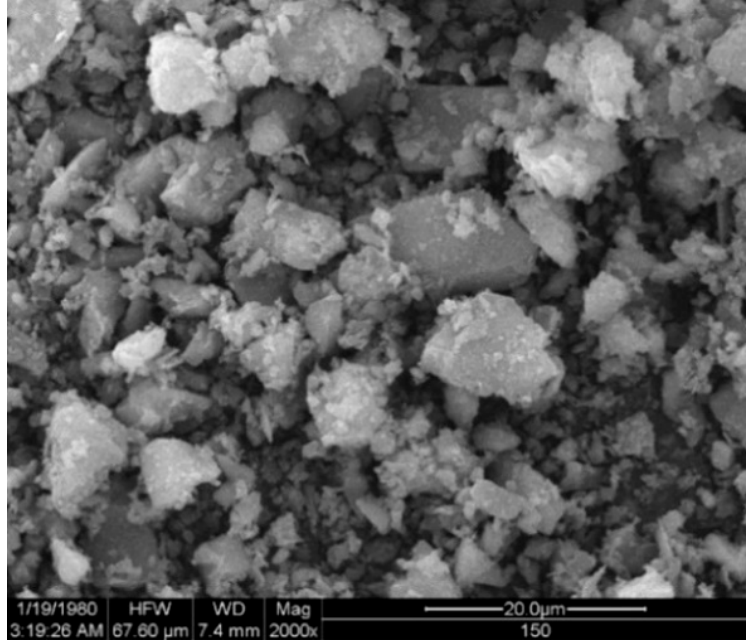

(a)

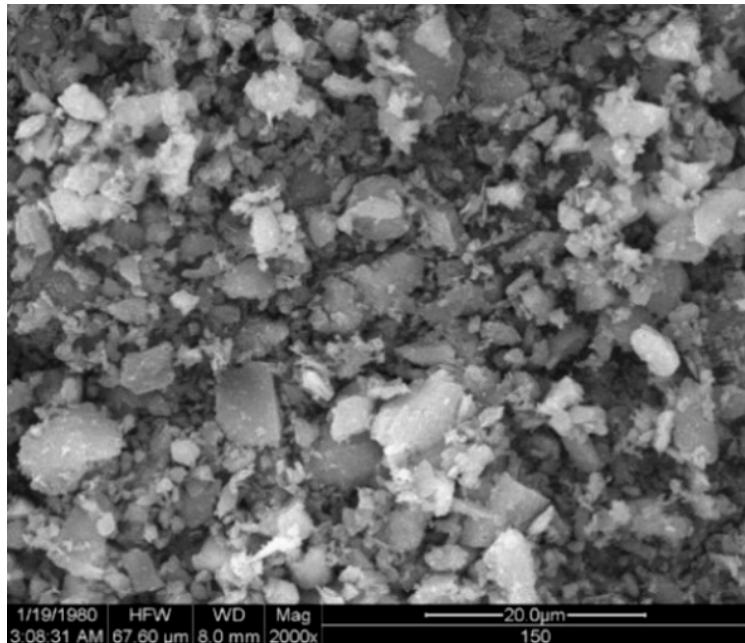

(b)

Figure 3. Particle morphology of CT after being ground for (a) $30 \mathrm{~min}$; and (b) $60 \mathrm{~min}$.

Two paste systems, I and II, prepared for hydration heat determination are listed in Tables 2 and 3, respectively. The hydration heat evolution rate and total hydration heat emission of the samples were measured by an isothermal calorimeter (TAM Air, TA Instruments Inc., New Castle, DE, USA) at $25^{\circ} \mathrm{C}$ within $72 \mathrm{~h}$, with a temperature fluctuation of less than $\pm 0.02{ }^{\circ} \mathrm{C}$. 


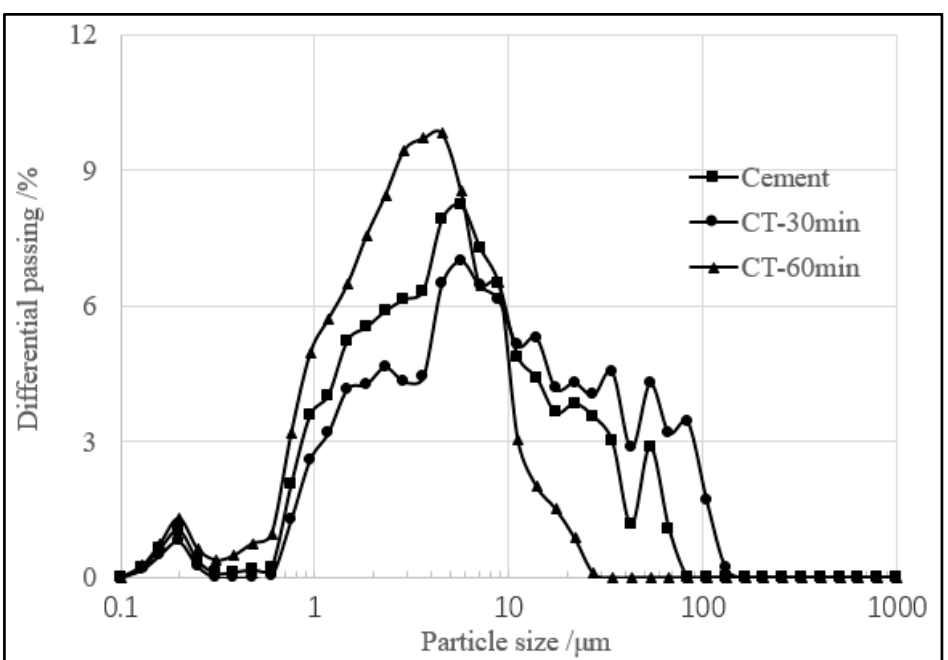

Figure 4. Particle size distribution curves of cement and CT.

Table 2. Mixture proportions I (samples cement-CT system (CTs))/Mass, \%.

\begin{tabular}{cccc}
\hline Sample & Grinding Time & CT & W/C \\
\hline CT3-15 & $30 \mathrm{~min}$ & $15 \%$ & 0.4 \\
CT3-30 & $30 \mathrm{~min}$ & $30 \%$ & 0.4 \\
CT3-45 & $30 \mathrm{~min}$ & $45 \%$ & 0.4 \\
CT6-15 & $60 \mathrm{~min}$ & $15 \%$ & 0.4 \\
CT6-30 & $60 \mathrm{~min}$ & $30 \%$ & 0.4 \\
CT6-45 & $60 \mathrm{~min}$ & $45 \%$ & 0.4 \\
C & $/$ & $0 \%$ & 0.4 \\
\hline
\end{tabular}

Table 3. Mixture proportions II (samples cement-GO system (CGs) and samples cement-GO-CT system (GCTs))/Mass, \%.

\begin{tabular}{cccccc}
\hline \multicolumn{2}{c}{ Sample } & GO Content & Cement & CT & W/C \\
\hline \multirow{6}{*}{ CGs } & C-0 & 0 & $100 \%$ & 0 & 0.4 \\
& C-1 & $0.01 \%$ & $100 \%$ & 0 & 0.4 \\
& C-2 & $0.02 \%$ & $100 \%$ & 0 & 0.4 \\
& C-3 & $0.03 \%$ & $100 \%$ & 0 & 0.4 \\
\hline \multirow{6}{*}{ GCTs } & $C^{*}-0$ & 0 & $70 \%$ & $30 \%$ & 0.4 \\
& CT $^{*}-1$ & $0.01 \%$ & $70 \%$ & $30 \%$ & 0.4 \\
& CT $^{*}-2$ & $0.02 \%$ & $70 \%$ & $30 \%$ & 0.4 \\
& CT $^{*}-3$ & $0.03 \%$ & $70 \%$ & $30 \%$ & 0.4 \\
\hline
\end{tabular}

Note: Taking CT6-30 in mixture proportions I for example, 6 indicates that the grinding time of CT is $60 \mathrm{~min}$, 30 represents that the mixing content of $\mathrm{CT}$ is $30 \%$; For $\mathrm{CT}^{*}-2$ in mixture proportions II, $\mathrm{CT}^{*}$ is the simplified name of CT6-30, 2 stands for $0.02 \%$ dosage of graphene oxide (GO).

\section{Results and Discussion}

\subsection{Characteristics of Hydration Heat Evolution}

Figure 5 shows the hydration heat evolution rate and total hydration heat of a cement-CT composite system (CTs) within $72 \mathrm{~h}$. The acceleration period and the time at which the induction period of CTs ended are shown in Figure 6. The rate of the second exothermic peak and the total hydration heat evolution at different hydration times determined from heat evolution curves are listed in Table 4. 
Table 4. Characteristic values of hydration heat evolution curves of samples at $25^{\circ} \mathrm{C}$.

\begin{tabular}{|c|c|c|c|c|c|c|c|c|c|}
\hline \multirow{2}{*}{ Sample } & \multirow{2}{*}{$\begin{array}{l}\text { Rate of the Second Heat } \\
\text { Emission Peak } q_{\max }(\mathrm{J} / \mathrm{g} \cdot \mathrm{h})\end{array}$} & \multicolumn{4}{|c|}{ Total Heat Release (J/g) } & \multicolumn{4}{|c|}{ Heat Release Per g of Cement (J) } \\
\hline & & $12 \mathrm{~h}$ & $48 \mathrm{~h}$ & $60 \mathrm{~h}$ & $72 \mathrm{~h}$ & $12 \mathrm{~h}$ & $48 \mathrm{~h}$ & $60 \mathrm{~h}$ & $72 \mathrm{~h}$ \\
\hline CT3-15 & 8.341 & 44.7 & 193.2 & 210.0 & 222.7 & 52.6 & 227.3 & 247.1 & 262.0 \\
\hline CT3-30 & 7.044 & 41.0 & 160.2 & 171.6 & 179.9 & 58.6 & 228.9 & 245.1 & 257.0 \\
\hline СТ3-45 & 5.529 & 34.9 & 130.0 & 139.0 & 145.4 & 63.5 & 236.4 & 252.7 & 264.4 \\
\hline CT6-15 & 8.541 & 48.2 & 200.6 & 217.5 & 229.8 & 56.7 & 236.0 & 255.9 & 270.4 \\
\hline CT6-30 & 7.203 & 43.7 & 166.2 & 179.4 & 189.3 & 62.4 & 237.4 & 256.3 & 270.4 \\
\hline CT6-45 & 5.768 & 37.6 & 132.0 & 141.4 & 148.3 & 68.4 & 240.0 & 257.1 & 269.6 \\
\hline C & 9.479 & 51.6 & 217.3 & 235.3 & 249.7 & 51.6 & 217.3 & 235.3 & 249.7 \\
\hline
\end{tabular}

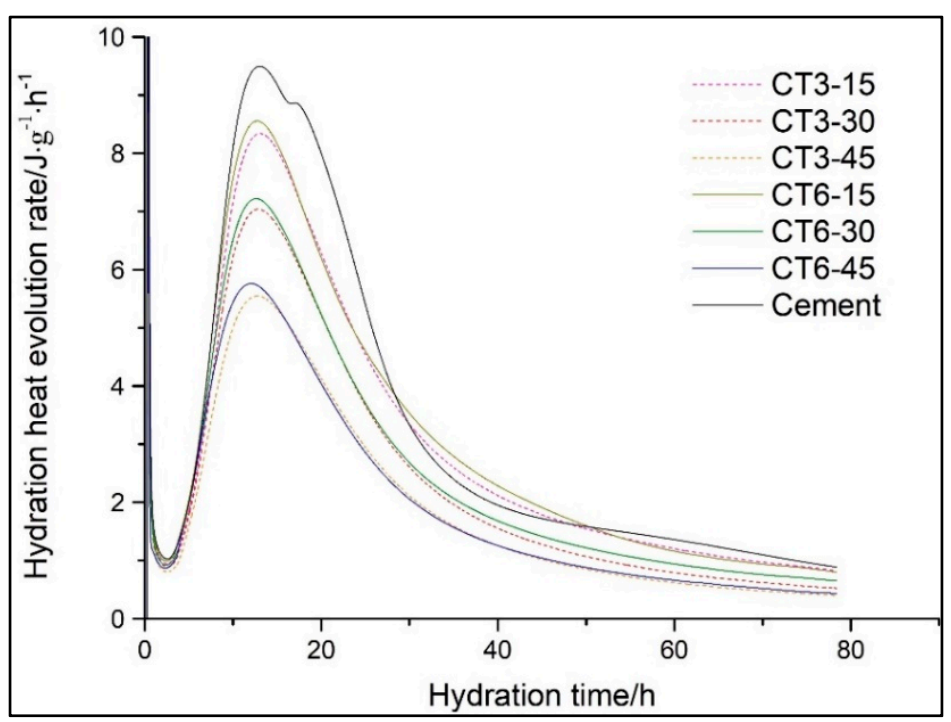

(a)

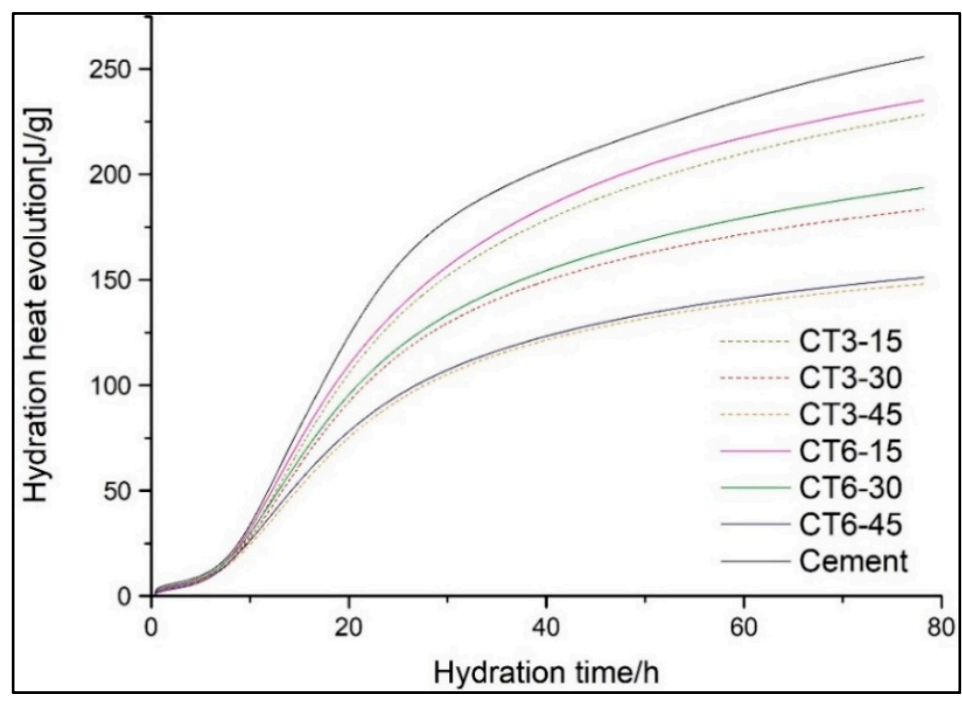

(b)

Figure 5. (a) Hydration heat evolution rate and (b) total hydration heat release of sample CTs.

As shown in Figure 5a, during the first few minutes after mixing the binder with water, a sharp exothermic peak corresponding to the first peak occurs in the curves and is attributed to the quick dissolution of cement and the quick formation of ettringite [15]. Then, the first peak declines dramatically and goes into the induction period. Figure 6 indicates that there is little difference among all the samples during the induction period. The duration of the induction of cement lasts for 
$1.94 \mathrm{~h}$ and ends at about $3.43 \mathrm{~h}$. With the increase in CT content, the duration of the induction period is prolonged from 2.21 to $3.1 \mathrm{~h}$. It may be caused because the cement content of the cementitious system decreases with the increase of CT content. Therefore, the dissolved $\mathrm{Ca}^{2+}$ concentration reduces and the time when $\mathrm{Ca}^{2+}$ reaches supersaturation extends, which leads to the ending time of the induction period being slightly prolonged [16-18].

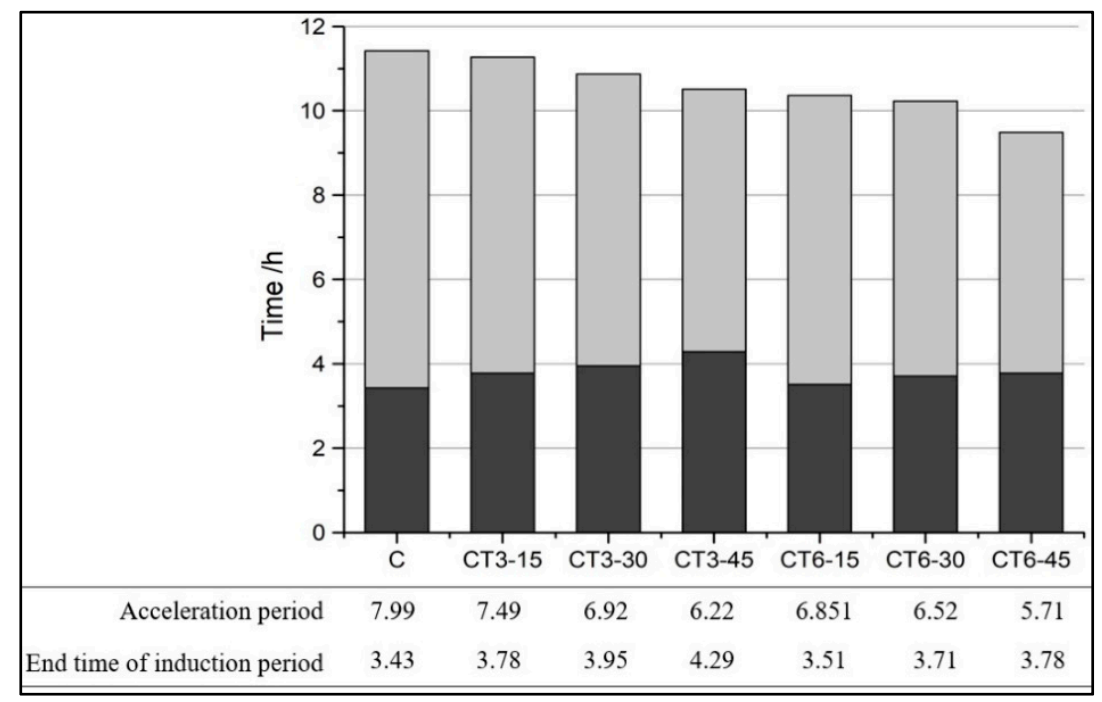

Figure 6. The acceleration period and end time of induction period.

After the acceleration period, comes the strong hydration reaction of $\mathrm{C}_{3} \mathrm{~S}$ and fast formation of C-S-H and $\mathrm{Ca}(\mathrm{OH})_{2}$ [19]. Owing to the sufficient reactant and water supply, the reaction during the acceleration period proceeds very quickly to form hydration products around the unreacted particles, which in turn postpones the hydration reaction. When the accelerating effect is equal to the delaying effect, the maximum value of the second exothermic peak is achieved. As a whole, the peak value improves and the duration time of the induction period is prolonged with the increase of CT content. In addition, the time at which the second exothermic peak is observed for all samples is slightly different and the hydration release curves tend to narrow with the increase in CT content, which corresponds to a low total hydration heat evolution. The low hydration activity and hydration degree of CT in the early stage, which mainly plays the filling role, is negligible and leads to the decrease in the overall quantity of reactants. Then, the reaction goes into the deceleration period and stable period, and the hydration reactions are much more steady and controlled by diffusion.

Moreover, it is interesting that the heat release per $\mathrm{g}$ of cement of the cement-CT binder clearly improves with the increase of CT content and strengthens slightly with the increase of CT fineness, as shown in Table 4. The actual water-cement ratio increases with the increase of the CT content, thus there is more water involved in the cement hydration, and the hydration rate of the cement at an early stage is accelerated even though the total hydration rate is delayed. CT particles, especially for the fine particles, can act as nucleation sites for cement hydration and accelerate its hydration. Similar results have been found for other mineral admixtures in our previous studies $[20,21]$ time taken to observe the second exothermic peak decreases with the increase of the specific surface area. It indicates that the high CT fineness can accelerate the early hydration of composite cementitious materials.

Figure $5 \mathrm{~b}$ shows that the total hydration heat evolution of a composite system containing CT is evidently lower than that of pure cement. Moreover, the total hydration heat evolution reduces with the increase of CT content but improves with the increase of CT fineness. As shown in Table 4, the heat emission at $72 \mathrm{~h}$ decreases by at least $8 \%$, from 249.72 to $229.75 \mathrm{~J} / \mathrm{g}$, after incorporating $15 \% \mathrm{CT}$ and decreases no less than $33 \%$, from 222.73 to $148.30 \mathrm{~J} / \mathrm{g}$, when the CT content increases from 15 to $45 \%$.

Figure 7 displays the hydration heat evolution rate and total hydration heat release of a cement-GO-CT composite system (GCTs). The second exothermic peak is slightly quickened as 
well as the value increases slightly with the GO content increasing from 0.01 to $0.03 \%$ in both pure cement and cement-CT composite system containing 30\% CT. GO lamellar can serve as nucleation sites for C-S-H to nucleate and crystalize, which promotes the hydration of the cementitious system. As shown in Figure 7b, the total hydration heat also increases slightly with the increase of GO content.

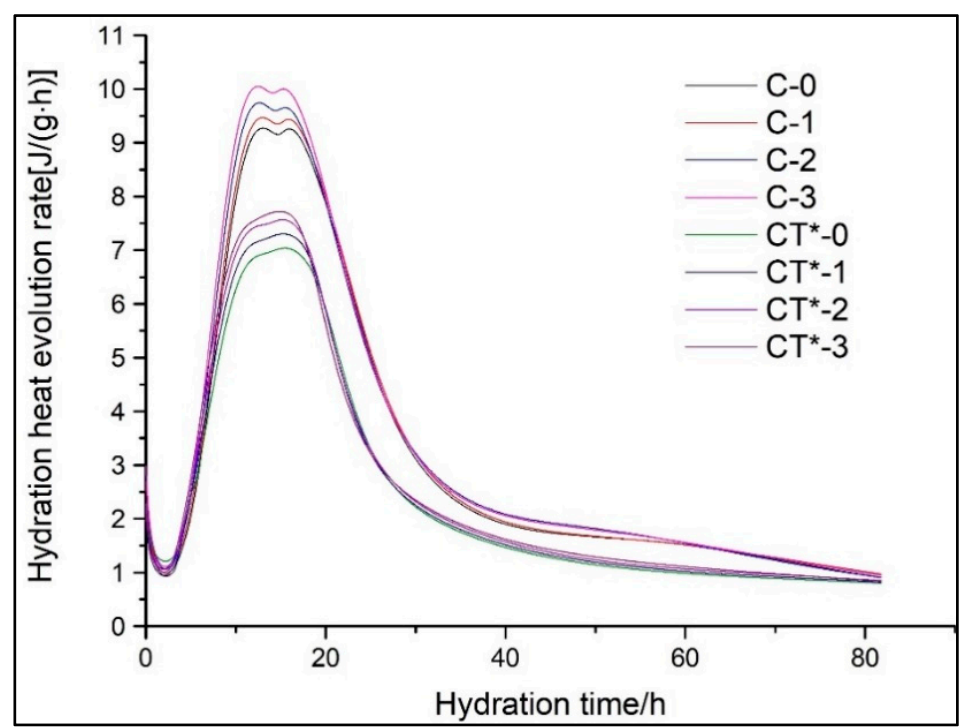

(a)

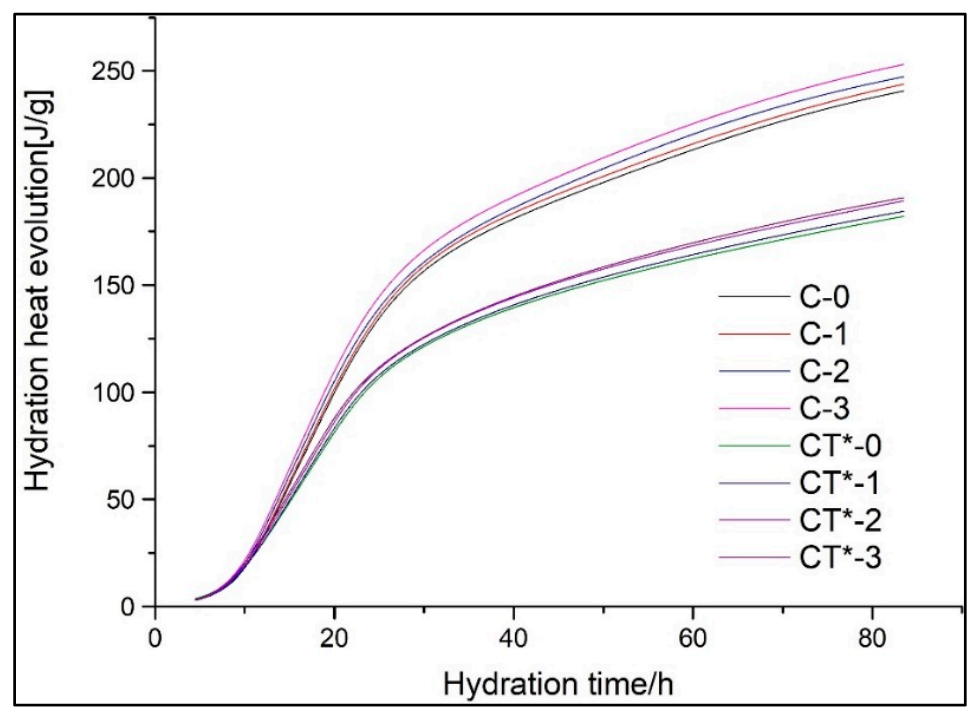

(b)

Figure 7. (a) Hydration heat evolution rate and (b) total hydration heat release of samples CGs and GCTs.

\subsection{Hydration Process Simulation}

\subsubsection{Hydration Kinetic Model}

A hydration kinetic model is often used to analyze the influence of various factors on the reaction rate and reaction direction during the hydration process, in order to reveal its control mechanism [22]. The Krstulovic-Dabic model assumes that three basic processes take place during the early hydration of the cement-based materials, namely nucleation and crystal growth (NG), phase boundary reaction (I), and diffusion (D) [23]. The three control processes may occur simultaneously, and can also occur alone or in pairs, but the hydration rate of the overall process depends on the one which reacts 
slowest. That is, the slowest reaction controls the reaction rate and mechanism at an early stage [24]. The Krstulovic-Dabic model also gives the basic kinetic equations to describe the three dominating processes of these three control processes as follows:

$$
\begin{array}{lr}
\text { NG : } & {[-\ln (1-\alpha)]^{1 / n}=K_{1}\left(t-t_{0}\right)=K_{1}^{\prime}\left(t-t_{0}\right)} \\
\text { I : } & {\left[1-(1-\alpha)^{1 / 3}\right]^{1}=K_{2} R^{-1}\left(t-t_{0}\right)=K_{2}^{\prime}\left(t-t_{0}\right)} \\
\text { D : } & {\left[1-(1-\alpha)^{1 / 3}\right]^{2}=K_{3} R^{-1}\left(t-t_{0}\right)=K_{3}^{\prime}\left(t-t_{0}\right)}
\end{array}
$$

where $\alpha$ is hydration degree; $K_{1}\left(K_{1}^{\prime}\right), K_{2}\left(K_{2}^{\prime}\right), K_{3}\left(K_{3}^{\prime}\right)$ is the reaction rate constant corresponding to the hydration processes NG, I, and D; $t$ is hydration time; $t_{0}$ is the time when the induction period ends; $R$ is the ideal gas constant; $n$ is the crystal growth index that reflects the geometrical crystal growth, $1 \leq n \leq 2$ [25].

When $\alpha$ is differentiated with respect to $t$ in the equations above, the hydration rate of each process is obtained as follows:

$$
\begin{aligned}
& \text { NG : } \quad \mathrm{d} \alpha / \mathrm{d} t=F_{1}(\alpha)=K_{1}^{\prime}(1-\alpha)[-\ln (1-\alpha)]^{\frac{n-1}{n}} \\
& \text { I : } \quad \mathrm{d} \alpha / \mathrm{d} t=F_{2}(\alpha)=3 K_{2}^{\prime}(1-\alpha)^{2 / 3} \\
& \mathrm{D}: \quad \mathrm{d} \alpha / \mathrm{d} t=F_{3}(\alpha)=3\left[K_{3}^{\prime}(1-\alpha)^{\frac{2}{3}}\right] / 2\left[1-(1-\alpha)^{\frac{1}{3}}\right]
\end{aligned}
$$

where $F_{1}(\alpha), F_{2}(\alpha)$, and $F_{3}(\alpha)$ represent the hydration processes NG, I, and D, respectively.

Based on the total hydration emission $Q(t)$ and the rate of hydration evolution $\mathrm{d} Q / \mathrm{d} t$ obtained by isothermal conduction calorimetry, the hydration degree $\alpha$ and hydration rate $\mathrm{d} \alpha / \mathrm{d} t$ required for the kinetic simulation of hydration process are determined by the following equations [26]:

$$
\begin{gathered}
\alpha(t)=\frac{Q(t)}{Q_{\max }} \\
\frac{\mathrm{d} \alpha}{\mathrm{d} t}=\frac{\mathrm{d} Q}{\mathrm{~d} t} \cdot \frac{1}{Q_{\max }} \\
\frac{1}{Q}=\frac{1}{Q_{\max }}+\frac{t_{50}}{Q_{\max } \cdot t}
\end{gathered}
$$

where this newly defined $Q(t)$ is the heat released from the end of the induction period. Due to the fact that the dissolution progress is so fast that it is not always possible to be detected. Meanwhile, the induction period is also thought to make a small contribution to the total heat. Therefore, this simulation is conducted from the beginning of the second peak, namely the ending of the induction period [27]; $Q_{\max }$ is the total hydration heat when the reaction has completely finished and is obtained by using the Knudsen extrapolation Equation (9) to linearly fit the hydration heat evolution curves [28]: where $t_{50}$ is the time required for half of $Q_{\max }$.

\subsubsection{Hydration Process Simulation of CTs}

In order to obtain the hydration kinetic equations of CTs, the $Q_{\max }$ and hydration degree $\alpha(t)$ is determined by Equations (7) and (9), respectively and successively at first, as shown in Figure 8 . Then, the kinetic parameters $K_{1}^{\prime}$ and $n$ during the nucleation and crystal growth (NG) process could be calculated by substituting $\alpha(t)$ into Equation (1) and linearly fitting the double logarithmic curve of $\ln [-\ln (1-\alpha)]$ vs. $\ln \left(t-t_{0}\right)$, as shown in Figure 9. $K_{2}^{\prime}$ for I process and $K_{3}^{\prime}$ for the D process can also be derived by plugging $\alpha(t)$ into Equations (2) and (3) and fitting the double logarithmic curve $\ln [1-(1-\alpha)]^{1 / 3}$ vs. $\ln \left(t-t_{0}\right)$ linearly. Finally, the hydration kinetic expressions, $F_{1}(\alpha), F_{2}(\alpha)$, and $F_{3}(\alpha)$, characterizing the hydration rate of the NG, I, and D processes as a function of the hydration 
degree $\alpha$, are acquired. The relationships of $F_{1}(\alpha), F_{2}(\alpha), F_{3}(\alpha)$ and $\mathrm{d} \alpha / \mathrm{d} t$ with $\alpha$ are also shown in Figure 10. The intersection point $\alpha_{1}$ is the turning point from NG to I, and $\alpha_{2}$ is the turning points from I to D.

From Figure 10, it can be seen that the practical hydration curves of $\mathrm{d} \alpha / \mathrm{d} t$ can be segmentally simulated by the theoretical curves, i.e., $F_{1}(\alpha), F_{2}(\alpha)$, and $F_{3}(\alpha)$. It means that the hydration kinetic model could basically simulate the hydration process of all samples and the hydration undergoes three processes, namely NG, I, and D, in order. The hydration of the composite system is controlled by multiple reaction mechanisms instead of a single one.

Cement reacts with water primarily, and $\mathrm{Ca}(\mathrm{OH})_{2}$ becomes supersaturated in a few minutes and then the hydrates grow from a fixed number of nuclei [29]. For the cement-CT binder, CT particles can also serve as nucleation sites for hydrates in addition to cement grains. After that, the hydration products grow rapidly on the limited number of nuclei [30,31]. As a result, the NG process dominates the hydration process. Owing to the continued replenishment of $\mathrm{Ca}^{2+}$ dissolved from unhydrated particles to supply the hydration reaction, the supersaturation state of $\mathrm{Ca}^{2+}$ remains constant. The reaction mainly occurs at the boundary between the solid hydrates and the liquids. At that time, the phase-boundary-controlled I process plays the leading role [32]. As the hydration process continues, the hydration products increase. In the meantime, a large amount of water is consumed. The ability of water and ions to reach the surface of the unhydrated particles through the hydrated layer also becomes difficult. Therefore, the diffusion process, D, becomes the dominant process.

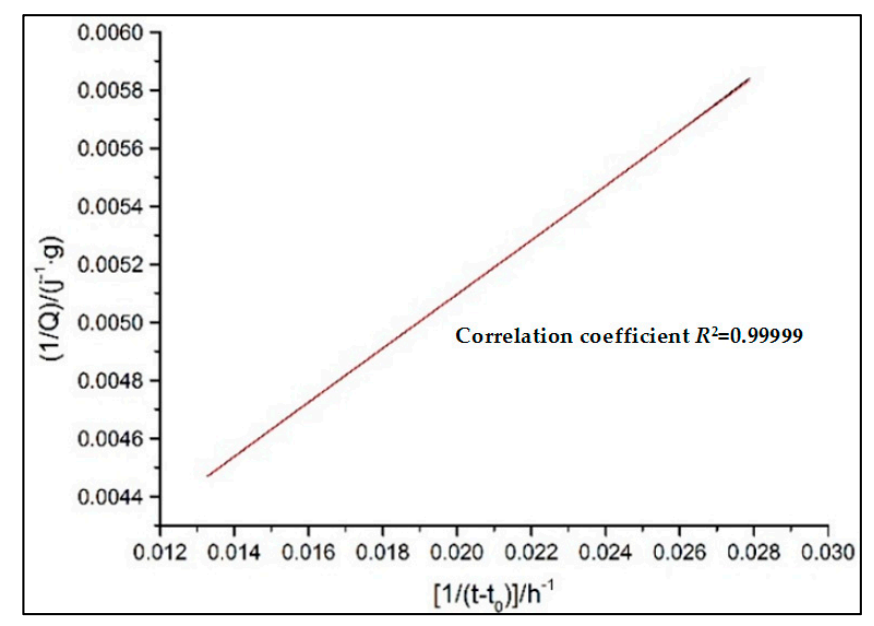

Figure 8. Determination of maximum hydration emission heat $Q_{\max }$ from linear regression.

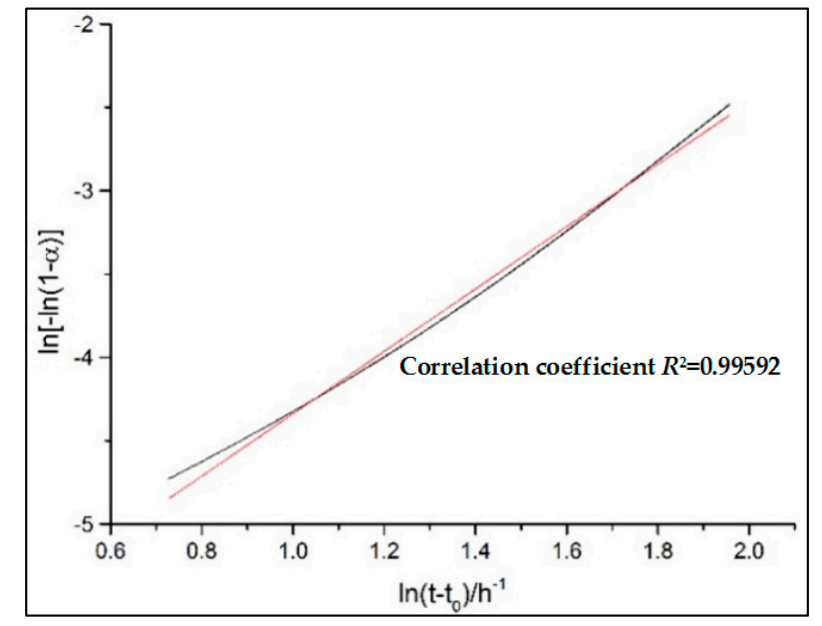

Figure 9. Determination of kinetic factors ( $n$ and $K_{1}^{\prime}$ ) of nucleation and crystal growth (NG) progress from linear regression. 


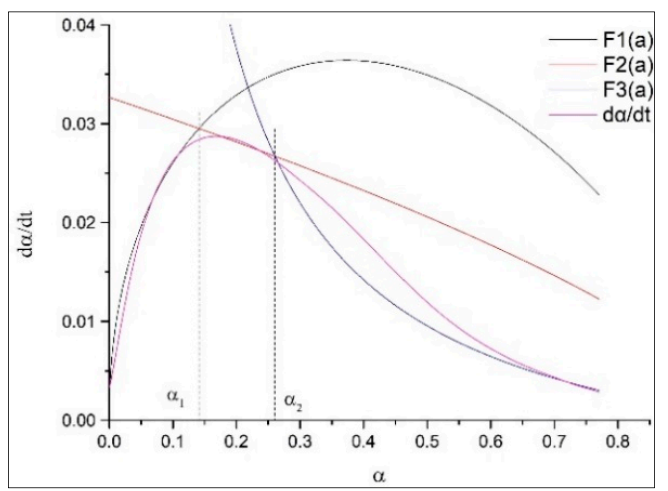

(a)

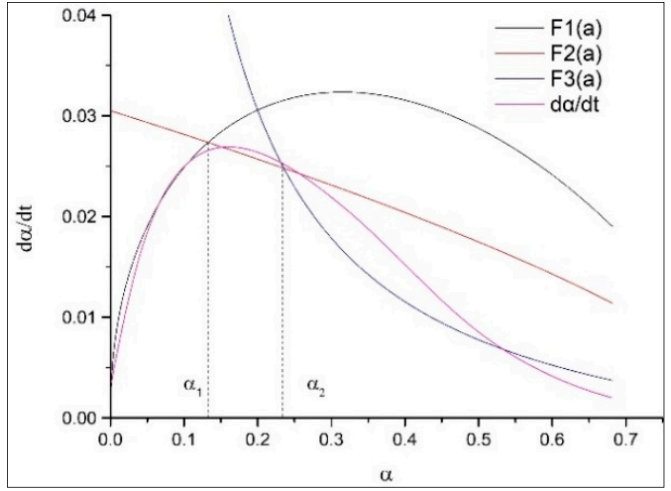

(c)

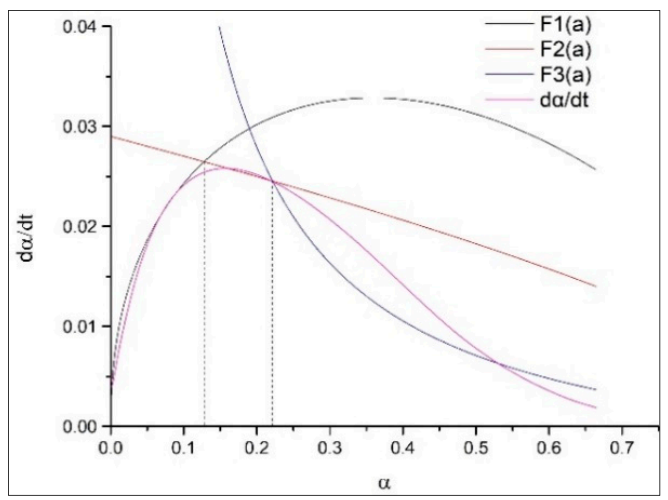

(e)

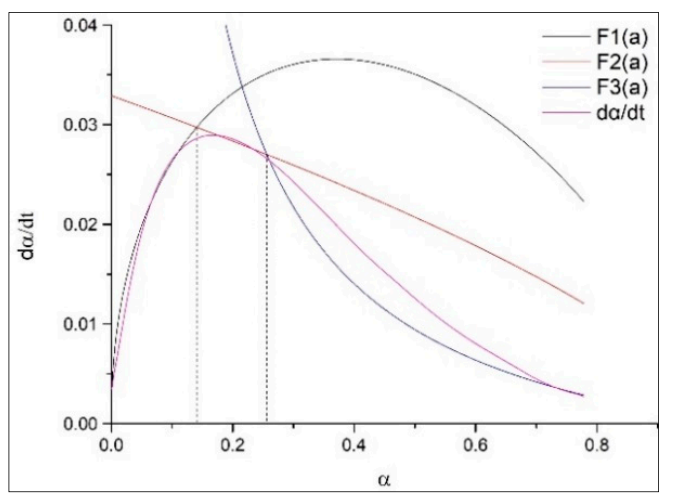

(b)

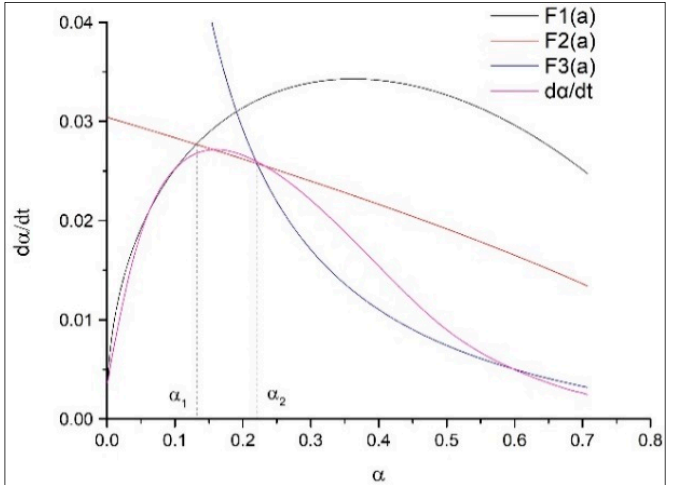

(d)

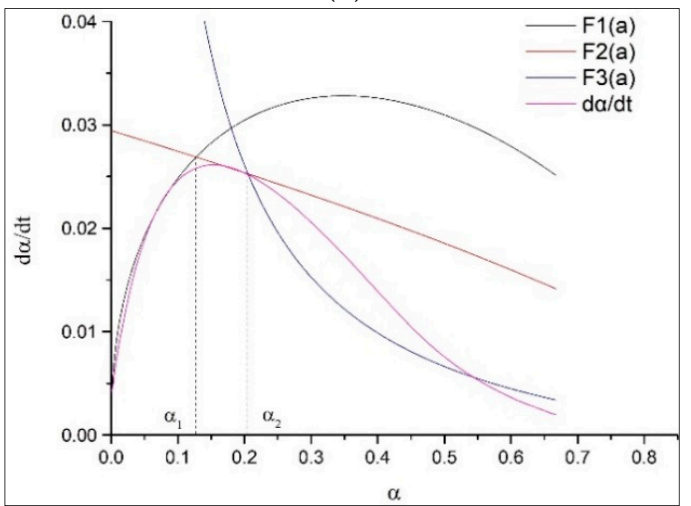

(f)

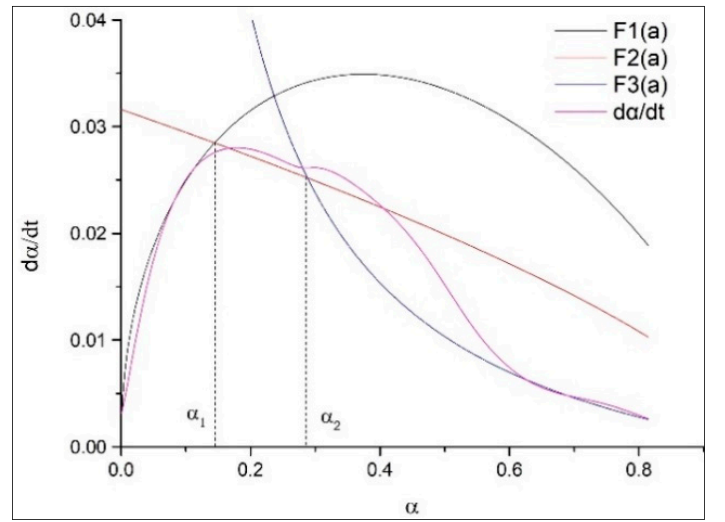

(g)

Figure 10. Hydration rate curves for samples CTs: (a) CT3-15; (b) CT6-15; (c) CT3-30; (d) CT6-30; (e) CT3-45; (f) CT6-45; (g) Cement. 
The kinetic parameters of the hydration process of sample CTs are listed in Table 5. The value of reaction order $n$ reduces with the increase of CT dosage while improving with the increase of CT fineness, which indicates that high fineness may affect the crystal growth geometry. The rate of chemical reaction during the NG process is very fast. The rate of the NG process is about $4-5$ times the rate of the I process, and about 20 times the rate of the $\mathrm{D}$ process. The hydration reaction during the NG process is an autocatalytic reaction. The continuous growth of the crystal nucleus leads to the increase of their boundaries, which in turn accelerates the hydration reaction of the NG process. Therefore, the hydration reaction during the NG process is fairly fast. However, the hydration reaction during the I process is mainly controlled by the ion concentration, crystal area, and growth space for hydrates. In comparison with the NG process, a lot of reactants and water are consumed and a large amount of hydration products are formed during the I process, leading to the ion concentration to decline and the growth space for hydration products to narrow. Thus, the hydration rate of the I process is much lower than that of the NG process. With the development of hydration, the hydration reaction proceeds to the D process. During this process, massive dense C-S-H is formed due to the hydration of cement and the pozzolanic reaction of $\mathrm{CT}$, which wraps on the surface of unreacted particles and makes the ion immobility difficult. As a result, the hydration rate during the $\mathrm{D}$ process is even lower than that during the I process.

Table 5. Kinetic parameters of the hydration process of sample CTs.

\begin{tabular}{ccccccccc}
\hline Sample & $\mathbf{N}$ & $\boldsymbol{k}_{\mathbf{1}}^{\prime}$ & $\boldsymbol{k}_{\mathbf{2}}^{\prime}$ & $\boldsymbol{k}_{\mathbf{3}}^{\prime}$ & $\boldsymbol{\alpha}_{\mathbf{1}}$ & $\boldsymbol{\alpha}_{\mathbf{2}}$ & $\boldsymbol{\alpha}_{\mathbf{2}}-\boldsymbol{\alpha}_{\mathbf{1}}$ & $\boldsymbol{Q}_{\max }^{\prime}$ \\
\hline Cement & 1.8843 & 0.04425 & 0.01053 & 0.00226 & 0.1456 & 0.2860 & 0.1404 & 305.983 \\
CT3-15 & 1.8521 & 0.04414 & 0.01088 & 0.00208 & 0.1412 & 0.2601 & 0.1189 & 290.475 \\
CT3-30 & 1.8188 & 0.04260 & 0.01016 & 0.00169 & 0.1312 & 0.2340 & 0.1028 & 261.525 \\
CT3-45 & 1.7522 & 0.04080 & 0.00966 & 0.00155 & 0.1280 & 0.2208 & 0.0928 & 215.114 \\
CT6-15 & 1.8788 & 0.04488 & 0.01097 & 0.00206 & 0.1404 & 0.2558 & 0.1154 & 295.598 \\
CT6-30 & 1.8401 & 0.04236 & 0.01014 & 0.00220 & 0.1318 & 0.2204 & 0.0886 & 265.947 \\
CT6-45 & 1.7988 & 0.04136 & 0.00982 & 0.00145 & 0.1280 & 0.2055 & 0.0775 & 220.486 \\
\hline
\end{tabular}

As shown in Table 5, $k_{1}^{\prime}$ decreases with the increase of CT dosage, implying that CT affects the nucleation and growth of hydrates. During the NG process, the reaction amount of CT is usually considered negligible because of its low pozzolanic activity [32]. With the increase of CT content, the cement dosage decreases, leading to the decrease of the $\mathrm{pH}$ value and the solubility of amorphous silicon as well as the growth rate of the crystal nucleus. Therefore, the growth rate during the NG process reduces with the increase of CT content. For the I process, the trend of the hydration rate, $k_{2}^{\prime}$, is consistent with that of $k_{1}^{\prime}$. The reaction rate of CT is much lower than that of cement. The amount of $\mathrm{CT}$ accounts for a large proportion of the increase in CT content, which leads to the reduction of the $k_{2}^{\prime}$ value. For the D process, a similar trend of $k_{3}^{\prime}$ is observed. A large amount of hydration products have been formed and the reaction becomes stable at this stage. On the one hand, the higher the content of cement is, the more intense the preceding hydration reaction and the denser the hydration products will be; therefore, the more difficult the ion mobility will be. Thus, the hydration reaction of the D process is weakened. On the other hand, a higher content of cement will greatly strengthen the overall hydration reaction of the cementitious system. When the positive effect leading to the improvement of the cement dosage and decrease of the CT content outweighs the negative, the whole reaction rate during the $\mathrm{D}$ process will decrease with the incorporation of $\mathrm{CT}$.

It is also noted that the hydration duration for both the NG process and I process is shortened with the increase of $\mathrm{CT}$ content, indicating that the hydration reaction of the composite binder containing $\mathrm{CT}$ transforms from the NG to I process and from the I to D process at a lower hydration degree with the increase of CT content. The replacement of cement by CT increases the effective water to cement ratio and provides more space for hydration products during the early hydration stage. Meanwhile, CT with high fineness can also act as nucleation sites for hydration products during the 
NG process [19]. Therefore, the controlling effect of the NG and I process is strengthened, which leads to a sharp exothermic rate and narrow hydration duration.

\subsubsection{Hydration Process Simulation of Composite Cementitious System Containing GO}

Figure 11 shows the simulated and practical hydration exothermic curves of composite cementitious materials containing GO and CT. It is observed that curves, $F_{1}(1), F_{2}(2)$, and $F_{3}(3)$, simulate the experimental hydration curves well, which validates that the hydration of both the cement-GO system (CGs) and cement-GO-CT system (GCTs) has a complicated process with a multiple reaction mechanism. In particular, the hydration process of CGs and GCTs after the induction period are the NG, I, and D processes in turn. Moreover, the hydration mechanism of the composite systems with GO is similar to that without it $\left(\mathrm{C}-0, \mathrm{CT}^{*}-0\right)$.

The kinetic parameters of the hydration process of composite cementitious materials are given in Table 6. The duration of the NG process is shortened while the I process is prolonged. For the CG system, the value of $\alpha_{1}$ decreases from 0.1483 to 0.1377 while $\alpha_{2}-\alpha_{1}$. increases from 0.2702 to 0.2833 while GO content increases from 0 to $0.03 \%$. With regard to the GCTs system, the value of $\alpha_{1}$ decreases from 0.1375 to 0.1306 , while $\alpha_{2}-\alpha_{1}$ increases from 0.2262 to 0.2413 along with the increase in the GO content from 0 to $0.03 \%$. It illustrates that GO promotes the nucleation and crystal growth process by acting as nucleation sites, and leads to a higher reaction rate but a shorter duration of the NG process. This also be confirmed by the fact that $k_{1}^{\prime}$ increases with the GO content. However, the hydration process during the I process is prolonged with the increase of GO dosage. It may be because GO improves the overall quantity of nucleation sites for crystal growth. In this case, the boundaries between the growing crystals and the solutions may also increase, leading to a longer duration to finish the I process. It also can be observed that the values of $\alpha_{1}$ and $\alpha_{2}-\alpha_{1}$ of GCTs are even less than those of CGs. It is also confirmed that the replacement of CT leads to a short hydration duration.

Overall, based on the data in Tables 5 and 6 , the hydration rates, $k_{1}^{\prime}, k_{2}^{\prime}$, and $k_{3}^{\prime}$ of the three controlling processes of the composite cementitious system decrease with the increase of CT content, but improve slightly with the increase of CT fineness. Although CT exerts an adverse effect on the early hydration, this can be slightly compensated for by the increase of CT fineness and can be overturned by the incorporation of GO. GO evidently accelerates the hydration of composite materials with the fact that $k_{1}^{\prime}, k_{2}^{\prime}$, and $k_{3}^{\prime}$ gradually increase with GO dosage. Additionally, with the increase of CT dosage as well as its fineness, the NG and I process are gradually shortened. GO enhances the controlling effect of the NG process of the cementitious systems with or without $\mathrm{CT}$, thus promoting the early hydration.

Table 6. Kinetic parameters of hydration process of sample CGs and CTGs.

\begin{tabular}{cccccccccc}
\hline \multicolumn{2}{c}{ Sample } & $\mathbf{N}$ & $\boldsymbol{k}_{\mathbf{1}}^{\prime}$ & $\boldsymbol{k}_{\mathbf{2}}^{\prime}$ & $\boldsymbol{k}_{\mathbf{3}}^{\prime}$ & $\boldsymbol{\alpha}_{\mathbf{1}}$ & $\boldsymbol{\alpha}_{\mathbf{2}}$ & $\boldsymbol{\alpha}_{\mathbf{2}}-\boldsymbol{\alpha}_{\mathbf{1}}$ & $\boldsymbol{Q}_{\max }^{\prime}$ \\
\hline \multirow{6}{*}{ CGs } & $\mathrm{C}-0$ & 1.806 & 0.04520 & 0.01137 & 0.00228 & 0.1483 & 0.2702 & 0.1219 & 306.112 \\
& $\mathrm{C}-1$ & 1.878 & 0.04599 & 0.01149 & 0.00233 & 0.1456 & 0.2742 & 0.1286 & 309.310 \\
& $\mathrm{C}-2$ & 1.881 & 0.04600 & 0.01151 & 0.00236 & 0.1404 & 0.2794 & 0.1390 & 312.495 \\
& $\mathrm{C}-3$ & 1.894 & 0.04705 & 0.01158 & 0.00241 & 0.1377 & 0.2833 & 0.1456 & 314.794 \\
\hline \multirow{6}{*}{$\mathrm{GCTs}$} & $\mathrm{CT}^{*}-0$ & 1.621 & 0.04060 & 0.01005 & 0.00165 & 0.1375 & 0.2262 & 0.0887 & 251.889 \\
& $\mathrm{CT}^{*}-1$ & 1.700 & 0.04182 & 0.01017 & 0.00172 & 0.1341 & 0.2333 & 0.0992 & 256.410 \\
& $\mathrm{CT}^{*}-2$ & 1.717 & 0.04235 & 0.01023 & 0.00179 & 0.1318 & 0.2401 & 0.1083 & 263.850 \\
& $\mathrm{CT}^{*}-3$ & 1.725 & 0.04251 & 0.01025 & 0.00181 & 0.1306 & 0.2413 & 0.1107 & 267.380 \\
\hline
\end{tabular}




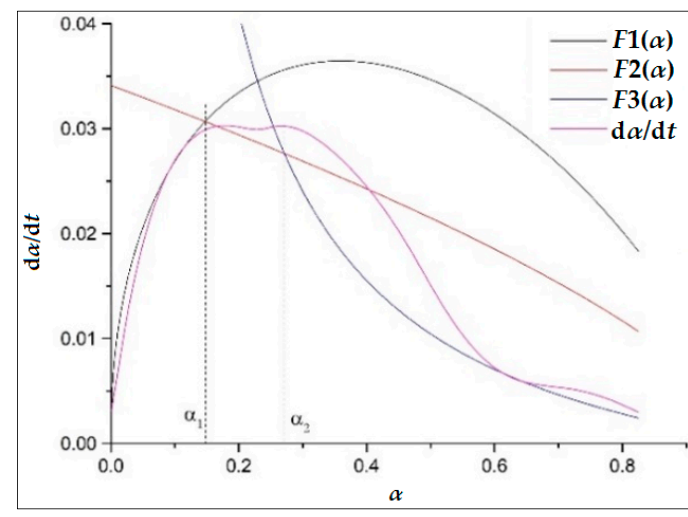

(a)

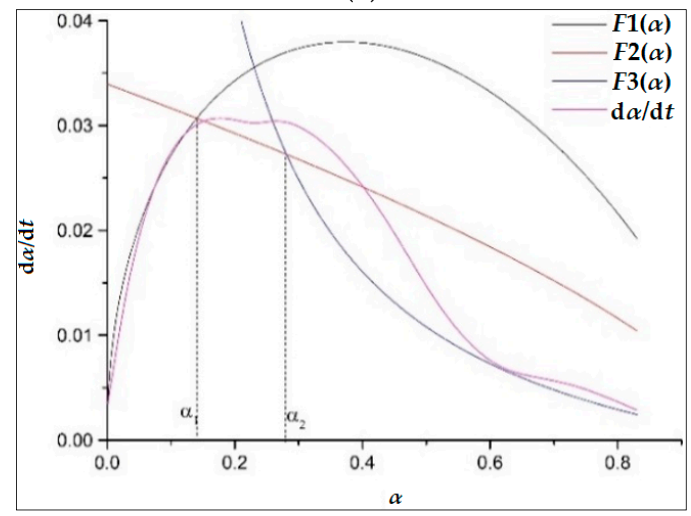

(c)

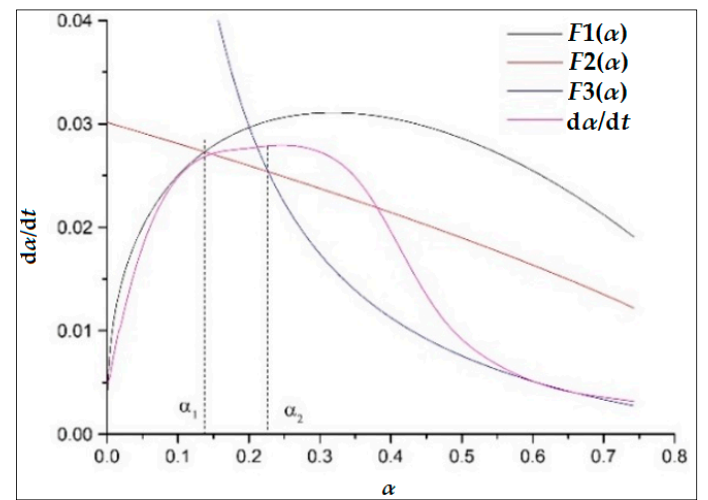

(e)

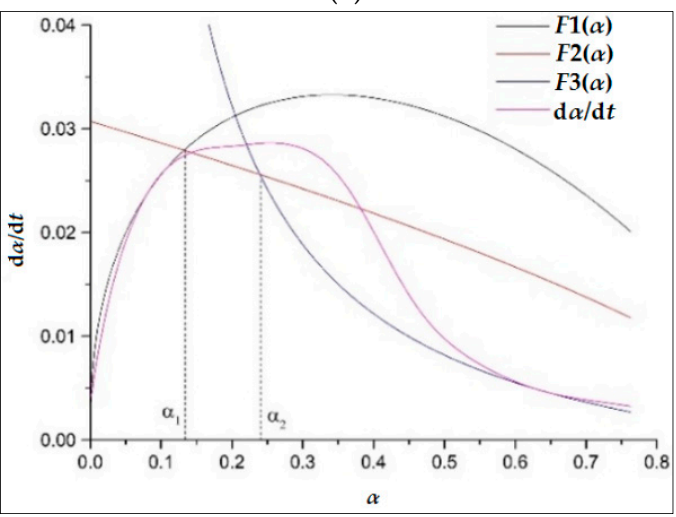

(g)

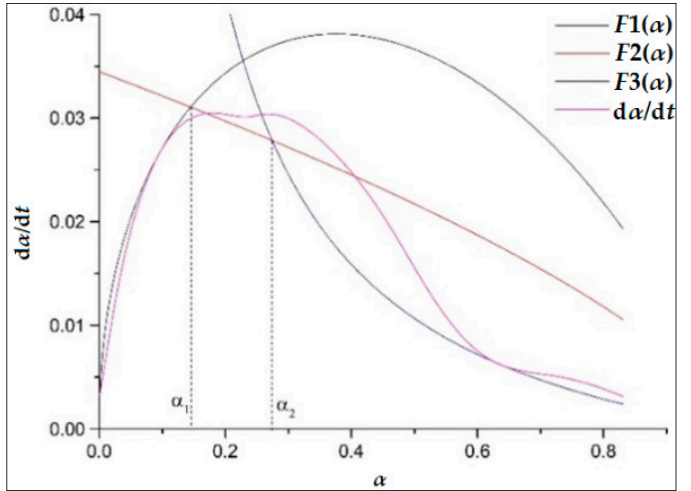

(b)

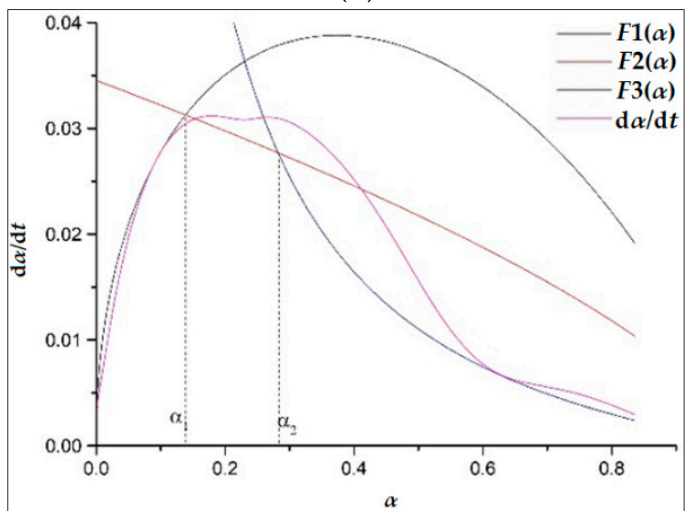

(d)

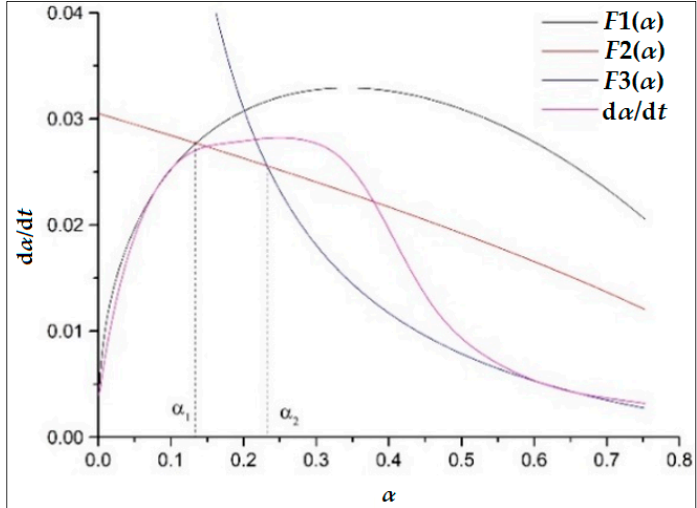

(f)

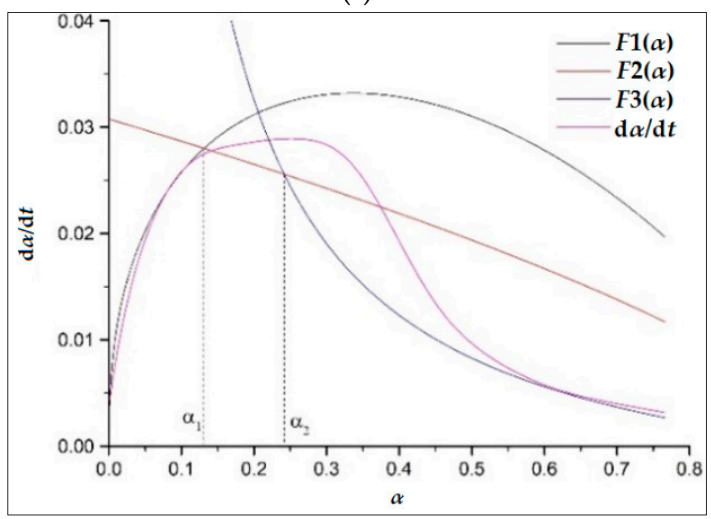

(h)

Figure 11. Hydration rate curves for samples of CGs and GCTs: (a) C-0; (b)C-1; (c)C-2; (d) C-3; (e) CT*-0; (f) $\mathrm{CT}^{*}-1 ;\left(\right.$ g) $\mathrm{CT}^{*}-2 ;$ (h) $\mathrm{CT}^{*}-3$. 


\section{Conclusions}

(1) Copper tailing powder, as a replacement for cement, reduces the early heat release rate and heat discharge of the cementitious system. The hydration rate and the total heat release improve with the decease of the content of copper tailing powder and the increase of the fineness of copper tailing powder. At the same time, graphene oxide can further improve the hydration rate and hydration heat of the cementitious system.

(2) The Krstulovic-Dabic kinetic model can be used to characterize the controlling process during the hydration. The hydration process of the composite cementitious materials containing copper tailing powder and graphene oxide is controlled by a multiple reaction mechanism, namely nucleation and crystal growth (NG), phase boundary reaction (I), and diffusion (D), in that order.

(3) The hydration rates, $k_{1}^{\prime}, k_{2}^{\prime}$, and $k_{3}^{\prime}$ of the three controlling processes reduce with the increase of the content of copper tailing powder, and improve with the increase of the fineness of copper tailing powder and the dosage of graphene oxide. Graphene oxide enhances the controlling effect on the nucleation and crystal growth process of the cementitious systems with or without copper tailing powder, thus promoting the early hydration.

Author Contributions: Conceptualization, S.L.; methodology, S.L.; validation, S.L.; formal analysis, Q.L. and X.Z.; investigation, Q.L.; resources, S.L.; data curation, Q.L.; writing—original draft preparation, Q.L. and X.Z.; writing-review and editing, S.L.; supervision, S.L.; project administration, S.L.; funding acquisition, S.L.

Funding: This research was funded by the National Key R\&D Program of China (2016YFC0401907), and Hubei Province Technical Innovation Project (2018AAA028).

Conflicts of Interest: The authors declare no conflict of interest.

\section{References}

1. Gordon, R.B. Production residues in copper technological cycles. Resour. Conserv. Recycl. 2002, 36, 87-106. [CrossRef]

2. Onuaguluchi, O.; Özgur, E. Recycling of copper tailings as an additive in cement mortars. Constr. Build. Mater. 2012, 37, 723-727. [CrossRef]

3. Yuan, S.L. Ways and tasks of comprehensive utilization and disposal of metal mine solid wastes. Express Inf. Mine Ind. 2004, 423, 1-11.

4. Chen, J.B.; Li, R.J.; Yu, L.H. The way of the survey and assessment of copper tailings resources and their application. J. Nat. Resour. 2012, 27, 1373-1381.

5. Yu, L.H.; Jia, W.L.; Xue, Y.Z. Survey and analysis of the cooper tailing resources in China. Met. Miner. 2009, 398, 179-181.

6. Wang, Y.; Tian, J.; Zhu, Y.C. Research on development and exploitation of copper mine tailing. Environ. Eng. 2015, 33, 623-627.

7. Onuaguluchi, O.; Eren, Ö. Cement mixtures containing copper tailings as an additive: Durability properties. Mater. Res. 2012, 15, 1029-1036. [CrossRef]

8. Onuaguluchi, O.; Özgur, E. Reusing copper tailings in concrete: Corrosion performance and socioeconomic implications for the Lefke-Xeros area of Cyprus. J. Clean. Prod. 2016, 112, 420-429. [CrossRef]

9. Lv, S.H.; Ma, Y.J.; Qiu, C.C. Effect of graphene oxide nanosheets of microstructure and mechanical properties of cement composites. Constr. Build. Mater. 2013, 49, 121-127. [CrossRef]

10. Lv, S.H.; Ma, Y.J.; Qiu, C.C.; Ju, H.B. Effects of graphene oxide on microstructure of hardened cement paste and its properties. Concrete 2013, 286, 41-54.

11. Lv, S.H.; Ma, Y.J.; Qiu, C.C. Study on reinforcing and toughening of graphene oxide cement-based composites. Funct. Mater. 2013, 15, 2227-2231.

12. Lv, S.H.; Liu, J.J.; Qiu, C.C.; Ma, Y.J.; Zhou, Q.F. Microstructure and mechanism of reinforced and toughened cement composites by nanographene oxide. Funct. Mater. 2014, 4, 4084-4089.

13. Liu, Q.; Xu, Q.F.; Li, X.M. Research progress of graphene and carbon nanotubes cement-based composites. China Concr. Cem. Prod. 2016, 239, 25-30. 
14. American Society for Testing and Materials, C618-15. Standard Specification for Coal Fly Ash and Raw or Calcined Natural Pozzolan for Use in Concrete; American Society for Testing and Materials: West Conshohocken, PA, USA, 2015.

15. Liu, S.H.; Wang, L.; Gao, Y.X. Influence of fineness on hydration kinetics of supersulfated cement. Thermochim. Acta 2015, 605, 37-42. [CrossRef]

16. Han, F.H.; Zhang, Z.; Wang, D.M. Hydration kinetics of composite binder containing slag at different temperatures. J. Therm. Anal. Calorim. 2015, 121, 815-827. [CrossRef]

17. Han, F.; He, X.; Zhang, Z.; Liu, J. Hydration heat of slag or fly ash in the composite binder at different temperatures. Thermochim. Acta 2017, 655, 202-210. [CrossRef]

18. Han, F.; Li, L.; Song, S.; Liu, J. Early-age hydration characteristics of composite binder containing iron tailing powder. Powder Technol. 2017, 315, 322-331. [CrossRef]

19. Liu, S.H.; Xie, G.S.; Wang, S. Effect of curing temperature on hydration properties of waste glass powder in cement-based materials. J. Therm. Anal. Calorim. 2015, 119, 47-55. [CrossRef]

20. Liu, S.H.; Xie, G.S.; Wang, S. Effect of glass powder on microstructure of cement pastes. Adv. Cem. Res. 2015, 27, 259-267. [CrossRef]

21. Liu, S.H.; Li, L.H. Influence of fineness on the cementitious properties of steel slag. J. Therm. Anal. Calorim. 2014, 117, 629-634. [CrossRef]

22. Bezjak, A. Nuclei growth model in kinetic analysis of cement hydration. Cem. Concr. Res. 1986, 16, 605-609. [CrossRef]

23. Krstulovic, R.; Dabic, P. A conceptual model of the cement hydration process. Cem. Concr. Res. 2000, 30, 693-698. [CrossRef]

24. Wang, X.Y.; Lee, H.S.; Park, K.B.; Golden, J.S. A multi-phase kinetic model to simulate hydration of slag-cement blends. Cem. Concr. Compos. 2010, 32, 468-477. [CrossRef]

25. Escalante-Garcia, J.I.; Fuente, A.F.; Alexer, G.; Fraire-Luna, P.E.; Guillermo, M. Hydration products and reactivity of blast-furnace slag activated by various alkalis. J. Am. Ceram. Soc. 2003, 86, 2148-2153. [CrossRef]

26. Schutter, G.D.; Taerwe, L. General hydration model for Portland cement and blast furnace slag cement. Cem. Concr. Res. 1995, 25, 593-604. [CrossRef]

27. Fernandez, J.A.; Puertas, F. Alkali-activated slag cements: Kinetic studies. Cem. Concr. Res. 1997, 27, 359-368. [CrossRef]

28. Fernandez, J.A.; Puertas, F.; Arteaga, A. Determination of kinetic equations of alkaline activation of blast furnace slag by means of calorimetric data. J. Therm. Anal. Calorim. 1998, 52, 945-955. [CrossRef]

29. Bullard, J.W. A determination of hydration mechanisms for tricalcium silicate using a kinetic cellular automaton model. J. Am. Ceram. Soc. 2008, 91, 2088-2097. [CrossRef]

30. Bullard, J.W.; Flatt, R.J. New insights into the effect of calcium hydroxide precipitation on the kinetics of tricalcium silicate hydration. J. Am. Ceram. Soc. 2010, 93, 1894-1903. [CrossRef]

31. Lothenbach, B.; Scrivener, K.; Hooton, R.D. Supplementary cementitious materials. Cem. Concr. Res. 2011, 41, 1244-1256. [CrossRef]

32. Thomas, J.J.; Biernacki, J.J.; Bullard, J.W.; Bishnoi, S.; Dolado, J.S.; Scherer, G.W.; Luttge, A. Modeling and simulation of cement hydration kinetics and microstructure development. Cem. Concr. Res. 2011, 41, 1257-1278. [CrossRef]

(C) 2018 by the authors. Licensee MDPI, Basel, Switzerland. This article is an open access article distributed under the terms and conditions of the Creative Commons Attribution (CC BY) license (http://creativecommons.org/licenses/by/4.0/). 